\title{
Amelioration of lipopolysaccharide-induced liver injury by aqueous rooibos (Aspalathus linearis) extract via inhibition of pro-inflammatory cytokines and oxidative stress
}

Olawale Razaq Ajuwon ${ }^{1,2}$, Oluwafemi Omoniyi Oguntibeju and Jeanine Lucasta Marnewick ${ }^{1 *}$

\begin{abstract}
Background: Acute liver injury occur after intraperitoneal administration of lipopolysaccharide (LPS). Oxidative stress and release of pro-inflammatory cytokines are both implicated in the pathogenesis of LPS-induced acute liver injury. This study investigated the ameliorative effect of fermented rooibos (Aspalathus linearis) extract on LPS-induced acute liver injury.
\end{abstract}

Method: Major phenolic compounds in the fermented rooibos extract by HPLC-DAD, as well as the in vitro antioxidant capacity were quantified before the start of the experiment. Male Wistar rats were randomized into 4 groups $(n=10$ per group) and given either water or fermented rooibos extract for 4 weeks before LPS injection. Hepatic function markers, including aminotransferases and lactate dehydrogenase, lipid peroxidation markers, antioxidant enzymes, glutathione redox status, as well as cytokine levels were monitored in the rats.

Results: Injection of LPS significantly increased serum levels of alanine aminotransferase (ALT), aspartate aminotransferase (AST) and lactate dehydrogenase (LDH). Oxidative stress, evidenced by increased thiobarbituric acid reactive substances (TBARS) measured as malondialdehyde (MDA) in plasma and liver, and decreased glutathione redox status (GSH: GSSG ratio) in whole blood and liver was induced in LPS-challenged rats. Furthermore, hepatic levels of pro-inflammatory response markers TNF- $a, I L-1 \beta$ and IL- 6 were increased significantly. Pre-feeding the fermented rooibos extract for 4 weeks decreased LPS-induced elevated levels of serum AST and LDH (significantly, $p<0.05$ ) as well as ALT marginally. Consuming rooibos caused an attenuation of the observed increase in plasma and hepatic MDA, decrease in whole blood and liver GSH:GSSG ratio, as well as the changes noted in various antioxidant enzymes. The elevation in TNF-a and IL-6 was significantly suppressed, indicating an inhibition of the induced inflammatory response by rooibos.

Conclusion: Overall, our data showed that aqueous rooibos extract attenuated LPS-induced liver injury possibly by modulating oxidative stress and suppressing pro-inflammatory cytokines formation.

Keyword: Aspalathus linearis, Anti-inflammatory, Cytokine, Hepatotoxicity, Lipopolysaccharide, Oxidative stress

\footnotetext{
* Correspondence: marnewickj@cput.ac.za

'Oxidative Stress Research Centre, Institute of Biomedical and Microbial Biotechnology, Faculty of Health and Wellness Sciences, Cape Peninsula University of Technology, PO Box 1906 Bellville 7535, South Africa Full list of author information is available at the end of the article
} 


\section{Background}

Lipopolysaccharide (LPS), an endotoxin, is a major glycolipid component of the outer cell wall of gram-negative bacteria, made up of a polysaccharide $\mathrm{O}$-chain and a biologically active lipid-A moiety, embedded within the bacterial membrane [1]. Endotoxemia-induced toxicity is characterized by injury to various organs, including liver, kidney and the brain, and it has been implicated as a contributing factor to bacterial infection resulting in sepsis, which is one of the major causes of morbidity and mortality in intensive care units [2]. Most of the toxicities observed in LPS-induced injury in the liver and systemic circulation has been attributed to toxic mediators produced by activated macrophages, including cytokines, such as tumor necrosis factor- $\alpha$ (TNF- $\alpha$ ), interleukins (IL-1, IL-6, IL-8, and IL-12), other proinflammatory molecules, including platelet-activating factor, prostaglandins, as well as reactive oxygen and nitrogen species (RONS), such as nitric oxide (NO) and superoxide radical [3]. The systemic inflammatory response triggered in the host by LPS is characterized by fever, leucocytosis, thrombocytopenia, changed metabolic responses and redox status impairment [2]. The consequences of impaired intracellular redox balance includes the generation of excessive RONS, induction of lipid peroxidation, DNA and protein damage, depletion of intracellular stores of endogenous antioxidants and inhibition of antioxidant enzymes [4].

The involvement of oxidative stress in injury associated with LPS suggests that dietary antioxidants may enhance the efficacy of treatment protocols designed to mitigate LPS-induced endotoxemia. Medicinal plants, fruits, vegetables, spices and teas are drawing a lot of attention because of their demonstrated health benefits, with scientific evidence demonstrating that phytochemicals in fruits, vegetables, spices and teas possess a high number of protective biological properties, including antioxidant, anti-inflammatory and other beneficial effects [5].

Rooibos (Aspalathus linearis) (Brum f) Dahlg. (Family Fabaceae; Tribe Crotolarieae) is a shrubby legume that is indigenous to the mountainous area of Clanwilliam in the Western Cape Province of South Africa. Traditionally, it is used to make a herbal beverage that is naturally caffeine-free, low in tannin and rich in unique polyphenolic antioxidants [6]. Due to its rich content of different compounds, some unique, with antioxidant and other health properties, rooibos is gaining more attention worldwide because of its potential for clinical uses. Aqueous extracts of rooibos have been shown to possess antioxidant activities in vitro [7]. In vivo evidence has shown that aqueous rooibos extracts are able to modulate oxidative stress by inhibiting lipid peroxidation and augmenting the glutathione redox status in rat sperm [8], rat liver [9] and in humans with an occupational risk [10] and at the risk of developing cardiovascular diseases [11]. Immunomodulatory effects of rooibos have been previously reported both in vitro and in vivo $[12,13]$, while a recent study also showed that rooibos and two of its flavonoids (luteolin and quercetin) were able to reduce the secretion of pro-inflammatory cytokine, IL- 6 and TNF- $\alpha$ using a LPS-stimulated macrophage model [14]. However, the evaluation of the in vivo antiinflammatory properties of rooibos remains to be sufficiently studied. Rooibos is most often consumed as a herbal tea and therefore an aqueous (hot-water) extract of fermented rooibos leaves and stems at a similar concentration as consumed by humans traditionally were used in this study to investigate its effectiveness in protecting against LPS-induced hepatic injury in Wistar rats.

\section{Methods}

\section{Preparation of the aqueous rooibos extract}

Fermented rooibos (superior grade) plant material was a generous gift from Rooibos Limited ( $\mathrm{Mr}$ Arend Redelinghuys, Clanwilliam, South Africa). An aqueous rooibos extract $(2 \%, \mathrm{w} / \mathrm{v})$, was prepared as reported previously [15] by the addition of freshly boiled tap water to tea leaves and stem at a concentration of $2 \mathrm{~g} /$ $100 \mathrm{~mL}$. The mixture was allowed to stand at room temperature for 30 minutes with constant stirring, filtered afterwards and dispensed into water bottles. The extract was fed to the rats ad libitum, with fresh extract prepared every second day.

\section{Phenolic content and total antioxidant capacity of aqueous rooibos extract}

The soluble solids content of the rooibos extract was determined gravimetrically as previously reported [15]. The total polyphenol content of the aqueous rooibos extract was determined using the Folin Ciocalteu's phenol reagent according to the method described by Singleton et al [16] and results expressed as mg gallic acid equivalents $/ \mathrm{mg}$ soluble solids. The flavanol content of the aqueous rooibos extract was determined colorimetrically at $640 \mathrm{~nm}$ using $p$-dimethylaminocinnamaldehyde (DMACA) according to the method of Treutter [17]. Results were expressed as mg catechin standard equivalents/mg soluble solids while the flavonol/flavones content was determined spectrophotometrically at $360 \mathrm{~nm}$ and results expressed as $\mathrm{mg}$ quercetin standard equivalents/mg soluble solids [18]. The total antioxidant capacity of the rooibos extract was assessed by measuring the oxygen radical absorbance capacity (ORAC), trolox equivalent antioxidant capacity (TEAC) and ferric ion reducing antioxidant power (FRAP) according to methods described by Ou et al. [19], Re et al. [20] and Benzie and Strain [21] respectively with some modifications as reported previously [9]. 


\section{HPLC analyses of aqueous rooibos extract}

Quantification of the major phenolic compounds in the aqueous rooibos extract was performed by high performance liquid chromatography (HPLC) on an Agilent 1200 series instrument (Agilent Technologies, Waldbron, Germany) equipped with an in-line degasser, quaternary pump, autosampler and a diode array and multiple wavelength detector, using a $5 \mu \mathrm{m}$ YMC-Pack Pro C18 (150 $\mathrm{mm} \times 4.6 \mathrm{~mm}$ i.d.) column for separation, with acquisition set at $287 \mathrm{~nm}$ for aspalathin and $360 \mathrm{~nm}$ for other components. The mobile phases consisted of water containing $300 \mu \mathrm{L} / \mathrm{L}$ trifluoroacetic acid (A) and methanol containing $300 \mu \mathrm{L} / \mathrm{L}$ trifluoroacetic acid (B). The gradient elution started at $95 \% \mathrm{~A}$, changing to $75 \%$ $\mathrm{A}$ after $5 \mathrm{~min}$ and to $20 \% \mathrm{~A}$ after $25 \mathrm{~min}$ and back to 95\% A after $28 \mathrm{~min}$. The flow rate was set at $0.8 \mathrm{~mL} /$ min, the injection volume was $20 \mu \mathrm{L}$ and the column temperature was set at $23^{\circ} \mathrm{C}$ [22]. Peaks were identified based on the retention time of the standards and confirmed by comparison of the wavelength scan spectra (set between $210 \mathrm{~nm}$ and $400 \mathrm{~nm}$ ).

\section{Animal treatment and experimental design}

Forty pathogen-free, male Wistar rats weighing $287 \pm 11 \mathrm{~g}$ were obtained from the Animal Unit of Stellenbosch University (Tygerberg Campus, South Africa). The rats were housed individually in stainless steel wired top and bottom cages fitted with polypropylene houses in an experimental animal holding facility maintained at a temperature of between $21-24^{\circ} \mathrm{C}$, with a $12 \mathrm{~h}$ light dark cycle. The rats were fed standard rat chow (SRC) ad libitum and had free access to tap water or the aqueous rooibos extract. After acclimatization for 1 week, the rats were randomized into four groups of 10 animals each, and treated for 28 days as follows: groups I (control) and II (LPS), were fed SRC and received tap water as the sole source of drinking fluid, while groups III (rooibos) and IV (rooibos + LPS) were fed SRC and received the aqueous rooibos extract $(2 \%, w / v)$ as the sole source of drinking fluid. On the $27^{\text {th }}$ day of the experiment, the rats were injected with either $0.1 \mathrm{~mL}$ of PBS vehicle (groups I and III) or $0.1 \mathrm{~mL}$ of LPS (Escherichia coli serotype 0111:B4, $0.5 \mathrm{mg} / \mathrm{kg}$ bw, i.p.) for groups II and IV to induce endotoxemia and liver injury [23]. Animals used in the study received humane care in accordance with the Principle of Laboratory Animal Care of the National Medical Research Council and the Guide for the Care and Use of Laboratory Animals of the National Academy of Sciences (National Institute of Health Publication no. 80-23, revised 1978). The study protocol was approved by the Cape Peninsula University of Technology's Faculty of Health and Wellness Sciences Research Ethics Committee (Ethics Certificate no: CPUT/ HAS-REC 2010/A003). The general conditions of the rats were monitored daily throughout the study and body weights recorded weekly and at sacrifice. Fluid intake was monitored at intervals of 2 days for the duration of the study period. At the end of the experimental period, fasted animals in all the groups were sacrificed 16 hours after the last LPS injection under sodium pentobarbital anesthesia $(0.15 \mathrm{ml} / 100 \mathrm{~g}$ body weight, i.p.). Approximately $8 \mathrm{ml}$ of blood was collected via the abdominal aorta and this was aliquoted into tubes with or without EDTA to obtain plasma or serum, respectively. The liver was excised, washed twice with ice-cold PBS $(10 \mathrm{mM}$ phosphate buffered saline $\mathrm{pH}$ 7.2) to remove residual blood, blotted to dry, weighed and immediately snap frozen in liquid nitrogen and stored at $-80^{\circ} \mathrm{C}$ for biochemical analyses.

\section{Preparation of liver homogenate}

Liver tissue was minced and homogenized (10\%, w/v) in $50 \mathrm{mM} \mathrm{NaH} \mathrm{PO}_{4}$ buffer containing $1 \mathrm{mM}$ EDTA and $0.5 \%$ Triton-X $(\mathrm{pH} 7.5)$ on ice. The homogenate was centrifuged at $10000 \mathrm{~g}$ for 10 minutes at $4^{\circ} \mathrm{C}$. The resulting supernatant was collected and stored at $-80^{\circ}$ $\mathrm{C}$ until used for biochemical assays. Protein contents of samples (erythrocyte and liver homogenate) were determined using a BCA protein assay kit (Pierce, Illinois, USA).

\section{Antioxidant capacity of plasma and liver homogenate}

To avoid protein interference in the antioxidant capacity assays, sub-samples of plasma and liver homogenates were precipitated with $0.5 \mathrm{M}$ perchloric acid (1:1, v/v) and centrifuged at $10000 \mathrm{~g}$ for $10 \mathrm{~min}$ at $4^{\circ} \mathrm{C}$. Supernatants were collected as protein free fractions [24]. Plasma total polyphenol content, as well as the ORAC (plasma and liver) were carried out according to the method of Singleton et al. [16] and Ou et al. [19], respectively.

\section{Liver function tests}

Serum ALT, AST and LDH were determined using standard diagnostic kits supplied by Medica Corporation, (Bedford, Mass., USA), on a Medica EasyRA automated clinical chemistry analyzer (Medica Corporation Bedford, Mass., USA).

\section{Lipid peroxidation, antioxidant enzymes activities and glutathione status determination}

Lipid peroxidation was estimated by measuring conjugated dienes (CD) and malondialdehyde (MDA). Plasma and liver MDA were assayed as MDA-TBA adducts using HPLC with a UV-visible detector according to a method of Khoschsorur et al. [25]. Results were expressed as $\mu$ mole/L or $\mu \mathrm{mole} / \mathrm{g}$ tissue in plasma and liver respectively. Conjugated dienes were estimated according to the method of Recknagel \& Glende [26] and results expressed as nmole/L or nmole/g tissue in plasma and liver respectively. 
Antioxidant enzyme activities were determined in the erythrocytes and liver homogenates. Catalase (CAT) activity was determined according to the method described by Aebi [27] in which the rate of decomposition of hydrogen peroxide was measured at $240 \mathrm{~nm}$. The activity of catalase was calculated using a molar extinction coefficient of $43.6 \mathrm{M}^{-1} \mathrm{~cm}^{-1}$ and results expressed as $\mu$ mole $\mathrm{H}_{2} \mathrm{O}_{2}$ consumed $/ \mathrm{min} / \mu \mathrm{g}$ protein. The activity of superoxide dismutase (SOD) was determined according to the method of Crosti et al. [28] and activity expressed as $\mathrm{U} / \mathrm{mg}$ protein. Glutathione peroxidase (GPx) activity was determined according to the method described by Ellerby \& Bredesen [29]. The activity of GPx was calculated using the extinction coefficient of $6.22 \mathrm{mM}^{-1} \mathrm{~cm}^{-1}$ and results expressed as nmole NADPH oxidized per min per $\mu \mathrm{g}$ protein. Glutathione reductase (GR) was assessed by the method of Staal et al. [30] and result expressed as $\mu$ mole NADPH oxidized per min per $\mu$ g protein using the extinction coefficient of $6.22 \mathrm{mM}^{-1} \mathrm{~cm}^{-1}$.

Hepatic and whole blood glutathione redox status was measured using a Bioxytech GSH/GSSG-412 $2^{\text {тм }}$ kit $\left(\right.$ OxisResearch $^{\mathrm{TM}}$, Portland, USA). This method was based on a method initially developed by Tietze [31] in which Ellman's reagent (5,5'-dithiobis-2-nitrobenzoic acid, DTNB) reacts with $\mathrm{GSH}$ to form a product spectrophotometrically detected at $412 \mathrm{~nm}$. Briefly, aliquots of whole blood without (total glutathione) or with $3 \mathrm{mM}$ freshly prepared 1-methyl-2-vinylpyridinium trifluoromethanesulfonate (M2VP, oxidized glutathione) were precipitated with $5 \%(\mathrm{w} / \mathrm{v})$ metaphosphoric acid (MPA). Liver samples were homogenized $(1: 10)$ in $15 \%(\mathrm{w} / \mathrm{v})$ trichloroacetic acid (TCA) containing $1 \mathrm{mM}$ EDTA for total glutathione determination and in $6 \%(\mathrm{v} / \mathrm{v})$ perchloric acid (PCA) containing freshly prepared $3 \mathrm{mM} \mathrm{M} 2 \mathrm{VP}$ and $1 \mathrm{mM}$ EDTA for oxidized glutathione (GSSG) determination on ice. After centrifugation at $10000 \mathrm{~g}$ for $10 \mathrm{~min}$, $50 \mu \mathrm{l}$ of supernatant (from deproteinized whole blood or liver homogenate) was added to $50 \mu \mathrm{L}$ of glutathione reductase $(1 \mathrm{U})$ and $50 \mu \mathrm{L}$ of $0.3 \mathrm{mM}$ DTNB. The reaction was initiated by addition of $1 \mathrm{mM} \mathrm{NADPH}$ to a final volume of $200 \mu \mathrm{L}$. The change in absorbance was monitored at $412 \mathrm{~nm}$ for $3 \mathrm{~min}$ and levels calculated using pure GSH and GSSG as standards. Reduced glutathione $(\mathrm{GSH})$ concentration was calculated as the difference between total glutathione and 2GSSG.

\section{Multiplex cytokine analysis}

Sub samples of livers were homogenized in 10 volumes of phosphate buffered saline (10 mM PBS, $\mathrm{pH} 7.2)$ and centrifuged twice at $15000 \mathrm{~g}$ for $15 \mathrm{~min}$ at $4^{\circ} \mathrm{C}$. The level of four inflammatory markers TNF- $\alpha$, IL- $1 \beta$, IL-6 and IL-10 were determined in these homogenates using customized Milliplex ${ }^{\mathrm{TM}}$ MAP rat cytokine kits (RCYTO$80 \mathrm{~K}$; Merck Millipore, St Charles, Missouri, USA), on the Bio Plex platform (Bio Plex ${ }^{\mathrm{Tm}}$, Bio Rad, Laboratories, Hercules, USA) following the manufacturer's instructions. After optimizations, liver homogenates were assayed undiluted, in a blinded manner. All analyte levels in the quality control reagents of the kits were within the expected ranges. The standard curve for all the analytes ranged from 3.2-10000 pg/ml. The analyses of the bead median fluorescence intensities were done using the Bio-Plex Manager software (version 4.1.1).

\section{Statistical analysis}

Values were expressed as mean \pm SD. Data were tested for normality and equality of variance using the Levene's Test. Differences between groups mean were estimated using one-way analysis of variance (ANOVA) followed by the Student-Newman-Keuls test for all pairwise comparisons. The Kruskal-Wallis test, a non-parametric analogue to the one-way ANOVA was used to test for group differences when data was not normally distributed. Result were considered statistically significant at $\mathrm{p}<0.05$, or marginally significant at $\mathrm{p}<0.1$. All the statistics were carried out using MedCalc v 12.2.1 software (MedCalc software bvba, Mariakerke, Belgium).

\section{Results}

Phenolic content and antioxidant capacity of aqueous rooibos extract

Table 1 shows the results for the phenolic content and in vitro antioxidant capacity of the fermented rooibos extract used in the study. The total polyphenol content is $1.06 \mathrm{mg} \mathrm{GAE} / \mathrm{mL}$ (equivalent to $0.372 \mathrm{mg} \mathrm{GAE} / \mathrm{mg}$ soluble solids) of which the flavonols and flavanols account for $45 \%$ and $17 \%$, respectively. The antioxidant capacity of the rooibos extract determined as ORAC, FRAP and TEAC values are also shown in Table 1. Figure 1a shows the HPLC profile of the aqueous fermented rooibos extract at $287 \mathrm{~nm}$, with aspalathin $(29.98 \pm 0.08 \mu \mathrm{g} / \mathrm{mL})$ as the most abundant flavonoid. Other major flavonoids include iso-orientin $(25.98 \pm 0.52 \mu \mathrm{g} / \mathrm{mL})$, orientin $(18.61 \pm 18.61 \mu \mathrm{g} / \mathrm{mL})$, hyperoside/rutin $(14.55 \pm 2.26 \mu \mathrm{g} / \mathrm{mL})$, vitexin $(6.07 \pm$ $1.05 \mu \mathrm{g} / \mathrm{mL})$, and iso-vitexin $(7.18 \pm 0.20 \mu \mathrm{g} / \mathrm{mL})$. Minor peaks corresponding to chrysoeriol, luteolin and quercetin are also shown on the chromatogram (Figure 1b).

\section{Daily fluid and phenolic intake}

The daily fluid and phenolic intake of normal and endotoxemic rats are presented in Table 2. Fluid intake, regardless of whether water or fermented rooibos was consumed, was similar across all the animal groups. Also total phenolic, flavonol and flavanol did not differ in the two groups of animals consuming the fermented rooibos. 
Table 1 Phenolic content and in vitro antioxidant capacity of aqueous rooibos extract

\begin{tabular}{ll}
\hline \multicolumn{2}{c}{ Aqueous rooibos extract } \\
\hline Constituents & Concentration \\
\hline Soluble solids $(\mathrm{mg} / \mathrm{mL})$ & $2.85 \pm 0.39$ \\
Total polyphenol $(\mathrm{mg} \mathrm{GAE} / \mathrm{mL})$ & $1.06 \pm 0.02$ \\
Flavonol $(\mathrm{mg} \mathrm{QE} / \mathrm{mL})$ & $0.48 \pm 0.01$ \\
Flavanol $(\mathrm{mg} \mathrm{CE} / \mathrm{mL})$ & $0.19 \pm 0.01$ \\
Aspalathin $(\mu \mathrm{g} / \mathrm{mL})$ & $29.98 \pm 0.08$ \\
Orientin $(\mu \mathrm{g} / \mathrm{mL})$ & $18.61 \pm 0.13$ \\
Iso-orientin $(\mu \mathrm{g} / \mathrm{mL})$ & $25.98 \pm 0.52$ \\
Vitexin $(\mu \mathrm{g} / \mathrm{mL})$ & $6.07 \pm 1.05$ \\
Iso-vitexin $(\mu \mathrm{g} / \mathrm{mL})$ & $7.18 \pm 0.20$ \\
Hyperoside $/ \mathrm{rutin}(\mu \mathrm{g} / \mathrm{mL})$ & $14.55 \pm 2.26$ \\
Quercetin $(\mu \mathrm{g} / \mathrm{mL})$ & $0.89 \pm 0.18$ \\
Luteolin $(\mu \mathrm{g} / \mathrm{mL})$ & $0.22 \pm 0.06$ \\
Chrysoeriol $(\mu \mathrm{g} / \mathrm{mL})$ & $0.25 \pm 0.01$ \\
ORAC $(\mu \mathrm{mol} \mathrm{AAE} / \mathrm{mL})$ & $1.69 \pm 0.03$ \\
FRAP $(\mu \mathrm{mol} \mathrm{TE} / \mathrm{mL})$ & $5.20 \pm 0.04$ \\
TEAC $(\mu \mathrm{mol} \mathrm{TE} / \mathrm{mL})$ & $4.79 \pm 0.33$ \\
\hline
\end{tabular}

Values are mean \pm SD. Soluble solid is a mean of 12 determinations while other parameters are mean of 5 determinations. AAE (ascorbic acid equivalent), CE (catechin equivalent), GAE (gallic acid equivalent), QE (quercetin equivalent), TE (trolox equivalent).

Weight parameters and serum levels of ALT, AST and LDH The effect of rooibos consumption on body weight gain, liver weight, relative liver weight and serum levels of liver function enzymes are depicted in Table 3. Consuming the fermented rooibos extract without LPS treatment did not have any adverse effect on any of the weight parameters, as well as the serum levels of ALT, AST and LDH. No mortality was recorded in the LPS-challenged groups within the 16 hours before sacrifice. Intraperitoneal injection of LPS did not have any adverse effect on the body weight gain, liver weight or relative liver weight of the rats when compared with the control rats. There was a significant elevation $(\mathrm{p}<0.05)$ in the serum levels of ALT, AST and LDH with the LPS challenge when compare to control rats, resulting in 56, 88 and 50\% significant $(\mathrm{p}<0.05)$ increases, respectively. Consumption of the fermented rooibos extract (with LPS challenge) significantly $(\mathrm{p}<0.05)$ reduced the elevation in serum AST (21\%) and LDH (28\%), while serum ALT was marginally $(\mathrm{p}<0.1)$ reduced by $19 \%$ when compared with rats injected with LPS only.

\section{Plasma and liver antioxidant capacity and lipid peroxidation markers}

The antioxidant capacity of plasma and liver homogenates were assessed as total polyphenol content and ORAC values (Table 4). LPS injection significantly $(\mathrm{p}<0.05)$ reduced the plasma total polyphenol content, with rooibos supplementation able to reverse this reduction to a level comparable to that of the control. The plasma and liver ORAC of rats challenged with LPS were not significantly different $(p>0.05)$ from that of the control rats, regardless of whether the animals were consuming rooibos or not. Table 4 also shows the effect of the fermented rooibos extract supplementation on plasma and hepatic lipid peroxidation in normal and endotoxemic rats. Lipid peroxidation was assessed as conjugated dienes (CD) and malondialdehyde (MDA) formation. Plasma and hepatic CDs were similar across all groups of animals. MDA levels were significantly $(\mathrm{p}<0.05)$ elevated in the plasma $(22 \%)$ and liver $(43 \%)$ of LPS rats compared with control rats. In LPS-challenged rats consuming the fermented rooibos extract, the plasma and hepatic elevation in MDA was significantly $(\mathrm{p}<0.05)$ reduced by 27 and $22 \%$, respectively.

\section{Antioxidant enzymes and glutathione status}

The effect of aqueous fermented rooibos extract consumption on antioxidant enzyme activities and glutathione redox status in the blood and liver of control and LPS-treated rats are shown in Table 5 . In the erythrocytes, SOD and CAT activities were not affected by LPS injection. However, the activities of GPx and GR were significantly $(\mathrm{p}<0.05)$ reduced in the LPS-treated rats when compared with the control rats. Consuming the aqueous rooibos extract marginally $(\mathrm{p}<0.1)$ increased the GPx and GR activities in the LPS-challenged rats. Hepatic SOD and GPx activities were significantly $(\mathrm{p}<0.05)$ decreased, while CAT activity was significantly $(\mathrm{p}<0.05)$ increased as a result of the LPS challenge. Consumption of fermented rooibos extract in LPS-challenged rats significantly $(\mathrm{p}<0.05)$ reversed the changes induced in hepatic SOD, CAT and GPx activities. In the blood, the LPS challenge resulted in a significantly $(\mathrm{p}<0.05)$ increased GSSG level of $18 \%$, while depleting the GSH level as well as the GSH: GSSG ratio by 34 and $39 \%$, respectively, when compared to the control rats. Consumption of the fermented rooibos extract in LPS-challenged rats restored the GSH and GSH: GSSG ratio to levels comparable to those of the control rats, while not showing any effect on GSSG levels. Although, hepatic GSH levels were not affected by the LPS challenge in the LPS only rats when compared to the control rats, hepatic GSSG levels were significantly $(\mathrm{p}<0.05)$ elevated. As a result, a significant $(\mathrm{p}<0.05)$ decrease in hepatic GSH: GSSG ratio was observed in the LPS only rats when compared to the control rats. Aqueous rooibos extract consumption in the LPS treated rats significantly reduced the elevation in GSSG and improved the GSH: GSSG ratio to values similar to those found in the control rats. 
a

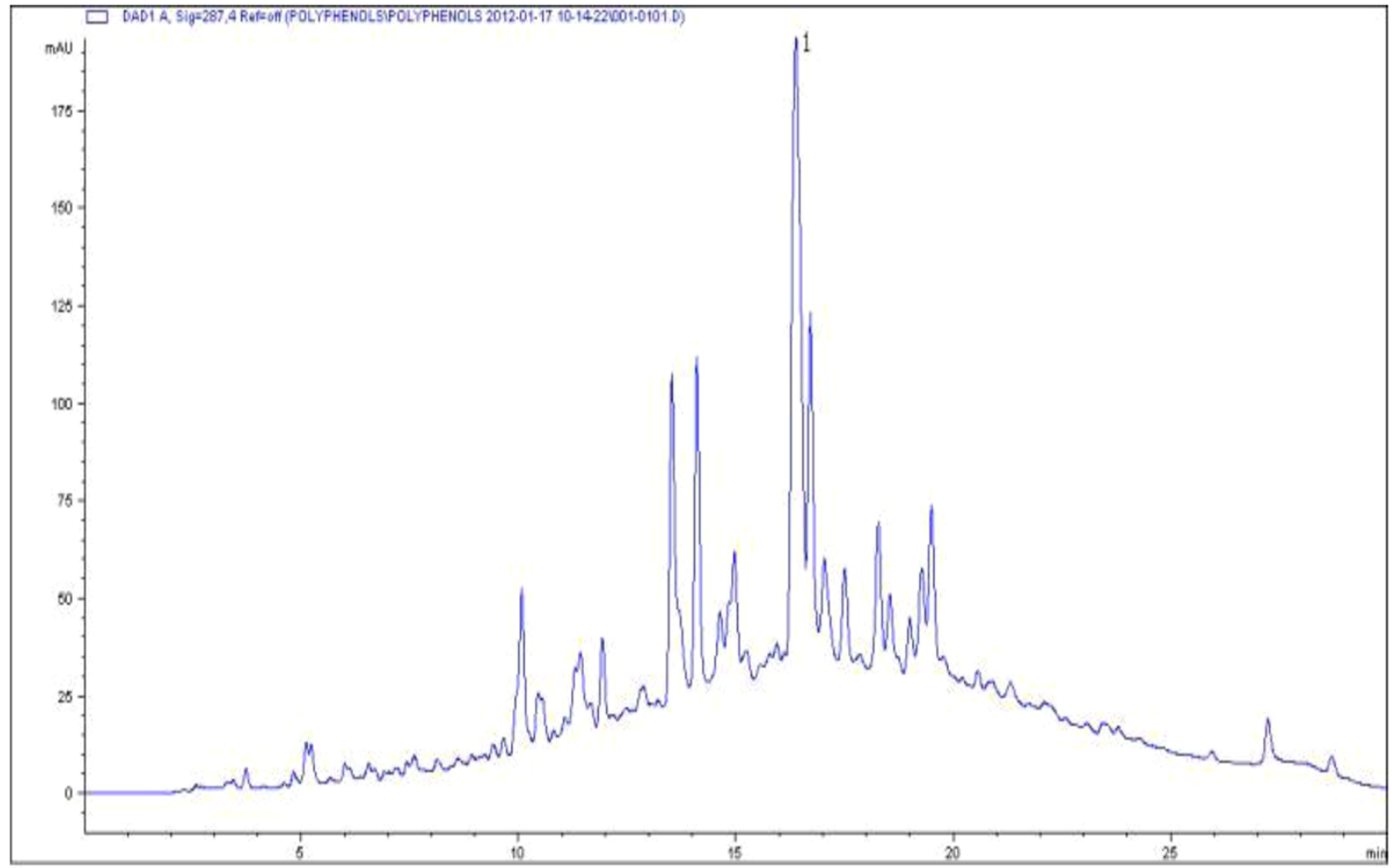

b

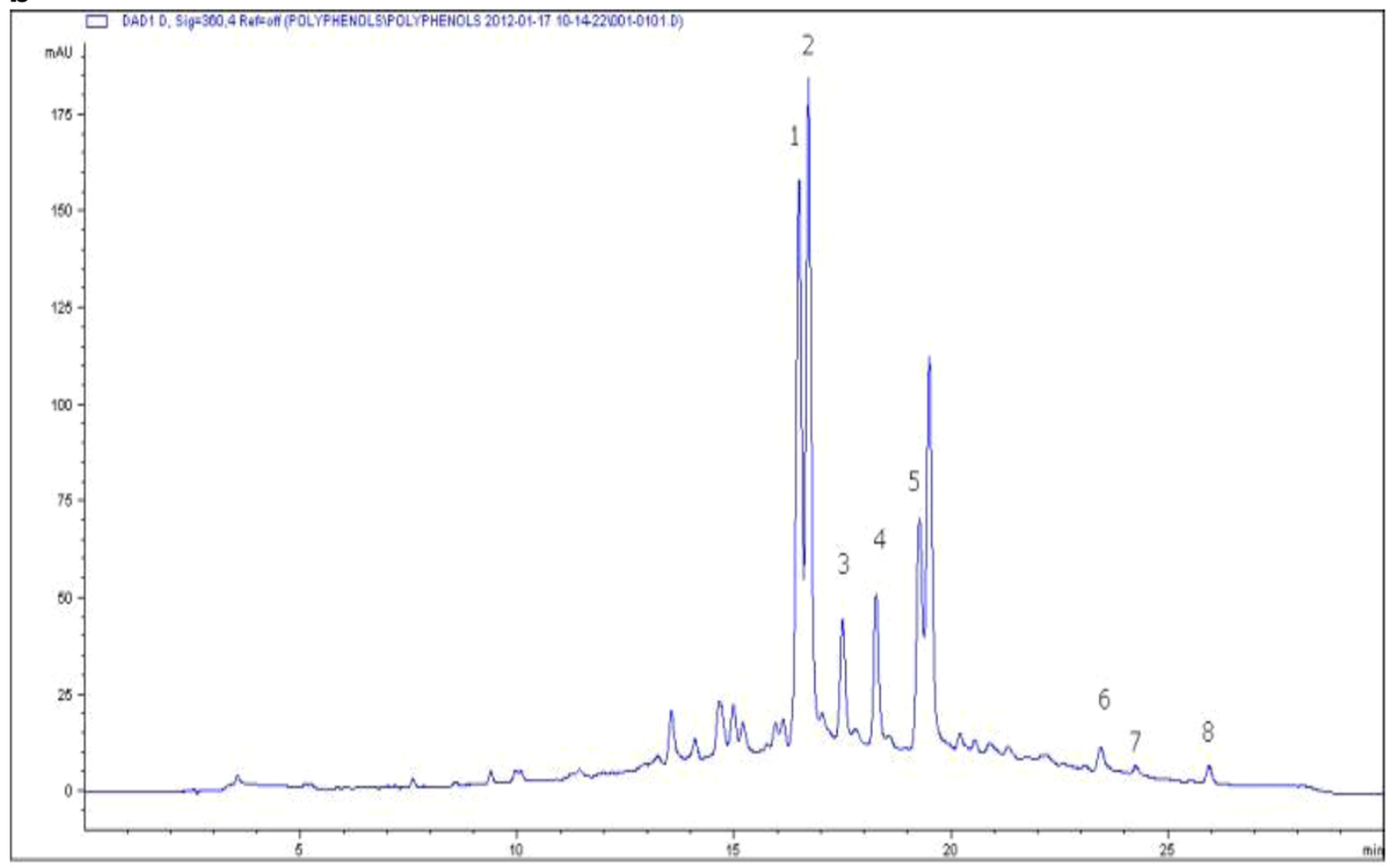

Figure 1 HPLC chromatogram of fermented rooibos extract used in the study showing (a) peak 1 for aspalathin at $287 \mathrm{~nm}$ (b) peaks for other flavonoids. 1, orientin; 2, iso-orientin; 3, vitexin; 4, isovitexin; 5, hyperoside/rutin; 6, quercetin; 7, luteolin; 8, chrysoeriol; at 360 nm. 
Table 2 Daily fluid and phenolic intakes of control and experimental rats

\begin{tabular}{lllll}
\hline Treatment & $\begin{array}{l}\text { Water/Rooibos intake/ } \\
\text { day/100 } \mathbf{~ B W ~} \mathbf{( m L})\end{array}$ & $\begin{array}{l}\text { Total phenolic intake } \\
(\mathbf{m g ~ G A E} / \text { day/100 } \mathbf{~ B W})\end{array}$ & $\begin{array}{l}\text { Flavonol intake } \\
\text { (mg QE/day/100 g BW) }\end{array}$ & $\begin{array}{l}\text { Flavanol intake } \\
\text { (mg CE/day/100 g BW) }\end{array}$ \\
\hline Control & $10.44 \pm 1.06$ & $\mathrm{ND}$ & $\mathrm{ND}$ & $\mathrm{ND}$ \\
LPS & $10.68 \pm 0.76$ & $\mathrm{ND}$ & $\mathrm{ND}$ & $\mathrm{ND}$ \\
Rooibos & $9.86 \pm 0.88$ & $10.45 \pm 0.93$ & $4.20 \pm 0.38$ & $1.59 \pm 0.14$ \\
Rooibos + LPS & $9.92 \pm 0.49$ & $10.51 \pm 0.52$ & $4.23 \pm 0.21$ & $1.60 \pm 0.08$
\end{tabular}

Calculations of the total phenolic, flavonol and flavanol intakes were calculated based on the soluble solid intake obtained from the average rooibos consumption per day. Values are mean \pm SD ( $n=10)$. ND (not determined), BW (body weight), CE (catechin equivalent), GAE (gallic acid equivalent), QE (quercetin equivalent), LPS (lipopolysaccharide).

\section{Hepatic cytokine levels}

Figure 2 shows the effect of the aqueous fermented rooibos extract consumption on hepatic cytokine levels in normal and LPS-treated rats. A significant $(\mathrm{p}<0.05)$ increase in the levels of TNF- $\alpha$ (45\%), IL-1 $\beta$ (419\%) and IL-6 (37\%) (Figures $2 \mathrm{a}, 2 \mathrm{~b}$ and $2 \mathrm{c}$, respectively) were observed in the liver of LPS-treated rats compared to control rats. Consuming the fermented rooibos extract significantly $(\mathrm{p}<0.05)$ reduced the LPS-induced elevation in TNF- $\alpha$ and IL- 6 to levels comparable to those observed in the negative control rats, however, no effect was seen in the IL-1 $\beta$ levels of LPS rats that consumed the rooibos extracts. The hepatic levels of the anti-inflammatory cytokine IL-10 (Figure 2d) was similar across all treatment groups, including the rooibos as well as the LPS and control groups.

\section{Discussion}

The focus of this study was to investigate the acute effects of LPS-induced hepatic oxidative stress and inflammatory responses, and the possible protection offered by oral administration of an aqueous fermented rooibos extract. The liver plays an important and central role in the regulation of entry and metabolism of LPS upon exposure. Mostly, the hepatic and systemic toxicities of LPS have been attributed to the release of chemical mediators such as superoxide, nitric oxide and proinflammatory cytokines, including TNF- $\alpha$, IL-1 $\beta$ and IL-6, which are all formed as a result of the binding of LPS to the CD14/LPS-binding protein and Toll-like receptor-4 (TLR4) on the surface of Kupffer cells [3,32].
Oxidative stress is a well-known mechanism of LPSinduced hepatic injury, and the redox imbalance produced may result in depletion of endogenous antioxidants such as the antioxidant enzymes and alteration of GSH redox status. Thus, augmenting the antioxidant defense system becomes necessary, especially during infections or periods of chronic oxidative insult. Whole extracts or isolated compounds from plants are popular applications to reverse and/or prevent hepatotoxicity and oxidative stress produced by noxious agents, such as LPS and these beneficial effects may be attributed to their antioxidant and anti-inflammatory properties.

In this study, it was observed that a single injection of LPS did not have a negative effect on the body weight gain, absolute liver weight and relative liver weight of the rats. However, LPS injection resulted in hepatic injury as indicated by an elevation in the levels of serum ALT, AST, and LDH, all circulating markers of hepatocyte injury. The hepatic function marker enzymes are cytoplasmic in nature but are usually leaked into circulation when liver damage occurs due to an alteration in membrane permeability. This observation is in accordance with several earlier reports which have shown that LPS induces hepatic damage, and as a consequence, increases the level of serum aminotransferases [33-35]. Results from the current study showed that supplementation with the aqueous fermented rooibos extract for 4 weeks prior to the LPS challenge, reversed the induced damage in the liver. Previous reports have demonstrated the ability of some polyphenol-rich plant extracts such as Artemisia absinthium [36], Salvia plebeia [37], Eucalyptus

Table 3 Effects of rooibos supplementation on weight parameters and serum marker enzymes in all experimental rats

\begin{tabular}{lllll}
\hline Treatment & Control & LPS & Rooibos & Rooibos + LPS \\
\hline Weight gain (g) & $89.21 \pm 17.31$ & $91.19 \pm 11.57$ & $90.01 \pm 3.53$ & $91.61 \pm 6.20$ \\
Liver weight (g) & $11.83 \pm 0.82$ & $12.36 \pm 1.25$ & $12.42 \pm 1.25$ & $12.64 \pm 0.65$ \\
RLW (\%) & $3.15 \pm 0.22$ & $3.36 \pm 0.43$ & $3.27 \pm 0.25$ & $3.30 \pm 0.14$ \\
ALT (U/L) & $105.69 \pm 28.93$ & $165.29 \pm 39.60^{*}$ & $109.31 \pm 11.32$ & $133.95 \pm 39.60^{\# \#}$ \\
AST (U/L) & $88.98 \pm 12.53$ & $167.22 \pm 34.82^{*}$ & $82.98 \pm 9.91$ & $131.64 \pm 33.92^{\#}$ \\
LDH (U/L) & $234.92 \pm 74.55$ & $351.36 \pm 81.64^{*}$ & $219.22 \pm 58.16$ & $252.67 \pm 76.62^{\#}$ \\
\hline
\end{tabular}

Values are mean \pm SD $(n=9-10)$. *Significantly different from control $(p<0.05)$. "Significantly different from LPS ( $<<0.05)$. $\left.{ }^{\# \# a r g i n a l l y ~ d i f f e r e n t ~ f r o m ~ L P S ~(~}<<0.1\right)$. ALT (alanine aminotransferase), AST (aspartate aminotransferase), LDH (lactate dehydrogenase), LPS (lipopolysaccharide), RLW (relative liver weight). 
Table 4 The effect of rooibos supplementation on in vivo total antioxidant capacity and markers of lipid peroxidation in plasma and liver of all experimental rats

\begin{tabular}{llllll}
\hline Tissue & Parameter & Control & LPS & Rooibos & Rooibos + LPS \\
\hline Plasma & Total polyphenol & $96.69 \pm 9.49$ & $73.37 \pm 6.83^{*}$ & $91.94 \pm 8.49$ & $85.69 \pm 12.24^{\#}$ \\
& ORAC & $1791.67 \pm 167.21$ & $1499.48 \pm 375.47$ & $1842.11 \pm 345.04$ & $1708.30 \pm 528.84$ \\
& CD & $85.79 \pm 5.81$ & $88.40 \pm 8.56$ & $84.34 \pm 10.66$ & $85.11 \pm 8.17$ \\
& MDA & $1.96 \pm 0.21$ & $2.40 \pm 0.20^{*}$ & $1.79 \pm 0.25$ & $1.76 \pm 0.32^{\#}$ \\
Liver & ORAC & $19.06 \pm 4.33$ & $17.40 \pm 4.14$ & $21.98 \pm 3.27$ & $18.51 \pm 4.50$ \\
& CD & $10.38 \pm 1.12$ & $12.78 \pm 0.79$ & $11.62 \pm 0.62$ & $11.84 \pm 0.47$ \\
& MDA & $64.83 \pm 5.46$ & $92.65 \pm 7.57^{*}$ & $64.44 \pm 7.57$ & $72.27 \pm 7.79^{\#}$ \\
\hline
\end{tabular}

Values are mean \pm SD $(n=9-10)$ *Significantly different from control $(p<0.05)$. "Significantly different from LPS ( $<<0.05)$. CD (conjugated dienes; $n m o l e / L$ in plasma, nmole/g tissue in liver), MDA (malondialdehyde; $\mu$ mole/L in plasma, $\mu$ mole/g tissue in liver), LPS (lipopolysaccharide), ORAC (oxygen radical absorbance capacity; $\mu$ mole trolox equivalent/L in plasma, $\mu$ mole trolox equivalent/g tissue in liver), Total polyphenol ( $\mu$ mole gallic acid equivalent/L).

globulus [38] and Hibiscus sabdariffa [39] in ameliorating LPS-induced hepatic injury. The protective effect of rooibos extract observed in our study may be due to the ability of the flavonoids in rooibos to stabilize and maintain the integrity of the hepatocyte membrane, as well as repair damaged hepatic tissues by stimulating hepatocyte regeneration and hepatocellular protein synthesis.

Results from a previous study have shown activation of Kupffer cells during endotoxemic episodes to result in the secretion of a wide variety of cytokines, including TNF- $\alpha$, IL-1 $\beta$ and IL-6 [40]. Up-regulation of cytokine production during LPS-induced endotoxemia is a wellknown phenomenon, and evidence has shown that increased levels of pro-inflammatory cytokines from neutrophils in the liver were associated with liver cell damage [41]. Tumor necrosis factor- $\alpha$, and IL-6 are two key cytokines involved in tissue damage during sepsis, although it has been suggested that TNF- $\alpha$ is the central mediator regulating other subsequent events [42]. In the present study, LPS significantly increased the level of hepatic TNF- $\alpha$, IL-1 $\beta$ and IL-6. Feeding rooibos for 4 weeks prior to the LPS challenge was able to reverse the increase in TNF- $\alpha$ and IL- 6 observed in the liver to a level that was comparable to what was seen in untreated control animals. However, no reversal was seen in the level of IL-1 $\beta$ with rooibos extract supplementation. Although Hendricks \& Pool [13], in an in vitro study reported that rooibos tea induced a higher IL- 6 and a lower IL-10 when added to endotoxin-stimulated white blood cells, literature supporting the inhibition of cytokines

Table 5 The effect of rooibos supplementation on antioxidant enzymes activity and glutathione redox status in the blood and liver of all experimental rats

\begin{tabular}{llllll}
\hline Tissue & Parameter & Control & LPS & Rooibos & Rooibos + LPS \\
\hline Blood & GAT & $0.21 \pm 0.05$ & $0.22 \pm 0.02$ & $0.27 \pm 0.04$ & $0.20 \pm 0.04$ \\
& SOD & $22.35 \pm 3.82$ & $22.25 \pm 3.25$ & $25.46 \pm 3.30$ & $19.24 \pm 1.72$ \\
GR & $0.15 \pm 0.01$ & $0.09 \pm 0.04^{*}$ & $0.15 \pm 0.03$ & $0.12 \pm 0.05^{\# \#}$ \\
& GPX & $0.18 \pm 0.03$ & $0.14 \pm 0.02^{*}$ & $0.23 \pm 0.03$ & $0.16 \pm 0.03^{\# \#}$ \\
& GSH & $906.11 \pm 173.54$ & $596.04 \pm 135.59^{*}$ & $905.09 \pm 135.20$ & $862.60 \pm 112.25^{\#}$ \\
Liver & GSSG & $173.47 \pm 34.25$ & $205.29 \pm 8.69^{*}$ & $185.45 \pm 35.99$ & $202.92 \pm 17.52$ \\
& GSH:GSSG & $4.76 \pm 1.22$ & $2.90 \pm 0.65^{*}$ & $5.18 \pm 1.86$ & $4.27 \pm 0.59^{\#}$ \\
& GAT & $0.11 \pm 0.01$ & $0.23 \pm 0.03^{*}$ & $0.11 \pm 0.03$ & $0.16 \pm 0.03^{\#}$ \\
& SOD & $55.01 \pm 5.27$ & $42.06 \pm 6.26^{*}$ & $61.50 \pm 3.85$ & $57.62 \pm 6.92^{\#}$ \\
& GR & $3.99 \pm 1.12$ & $2.69 \pm 0.62$ & $3.80 \pm 0.80$ & $3.37 \pm 0.79$ \\
& GPX & $0.16 \pm 0.02$ & $0.12 \pm 0.02^{*}$ & $0.16 \pm 0.01$ & $0.15 \pm 0.01^{\#}$ \\
& GSH & $6.38 \pm 0.58$ & $6.37 \pm 0.83$ & $7.29 \pm 0.96$ & $7.41 \pm 0.75$ \\
& GSSG & $0.32 \pm 0.10$ & $0.46 \pm 0.09^{*}$ & $0.28 \pm 0.04$ & $0.35 \pm 0.08^{\#}$ \\
& GSH:GSSG & $21.42 \pm 6.32$ & $13.64 \pm 2.39^{*}$ & $25.64 \pm 4.66$ & $21.98 \pm 5.34^{\#}$ \\
\hline
\end{tabular}

Values in columns are mean \pm SD $(n=9-10)$. ${ }^{*}$ Significantly different from control $(P<0.05)$. "Significantly different from LPS ( $\left.p<0.05\right)$. ${ }^{\# \#}$ Marginally different from LPS $(\mathrm{p}<0.1)$. CAT (catalase, $\mu$ mole $\mathrm{H}_{2} \mathrm{O}_{2}$ consumed $/ \mathrm{min} / \mu \mathrm{g}$ protein), GR (glutathione reductase, $\mu$ mole NADPH oxidized/min/ $\mu \mathrm{mg}$ protein), SOD (superoxide dismutase, U/mg protein), GPx (glutathione peroxidase, nmole NADPH oxidized/min/ $\mu$ g protein). GSH (reduced glutathione, $\mu \mathrm{mole} / \mathrm{L}$ in blood, $\mu \mathrm{mole} / \mathrm{g}$ tissue in liver), GSSG (oxidized glutathione, $\mu$ mole/L in blood, $\mu$ mole/g tissue in liver), LPS (lipopolysaccharide). 


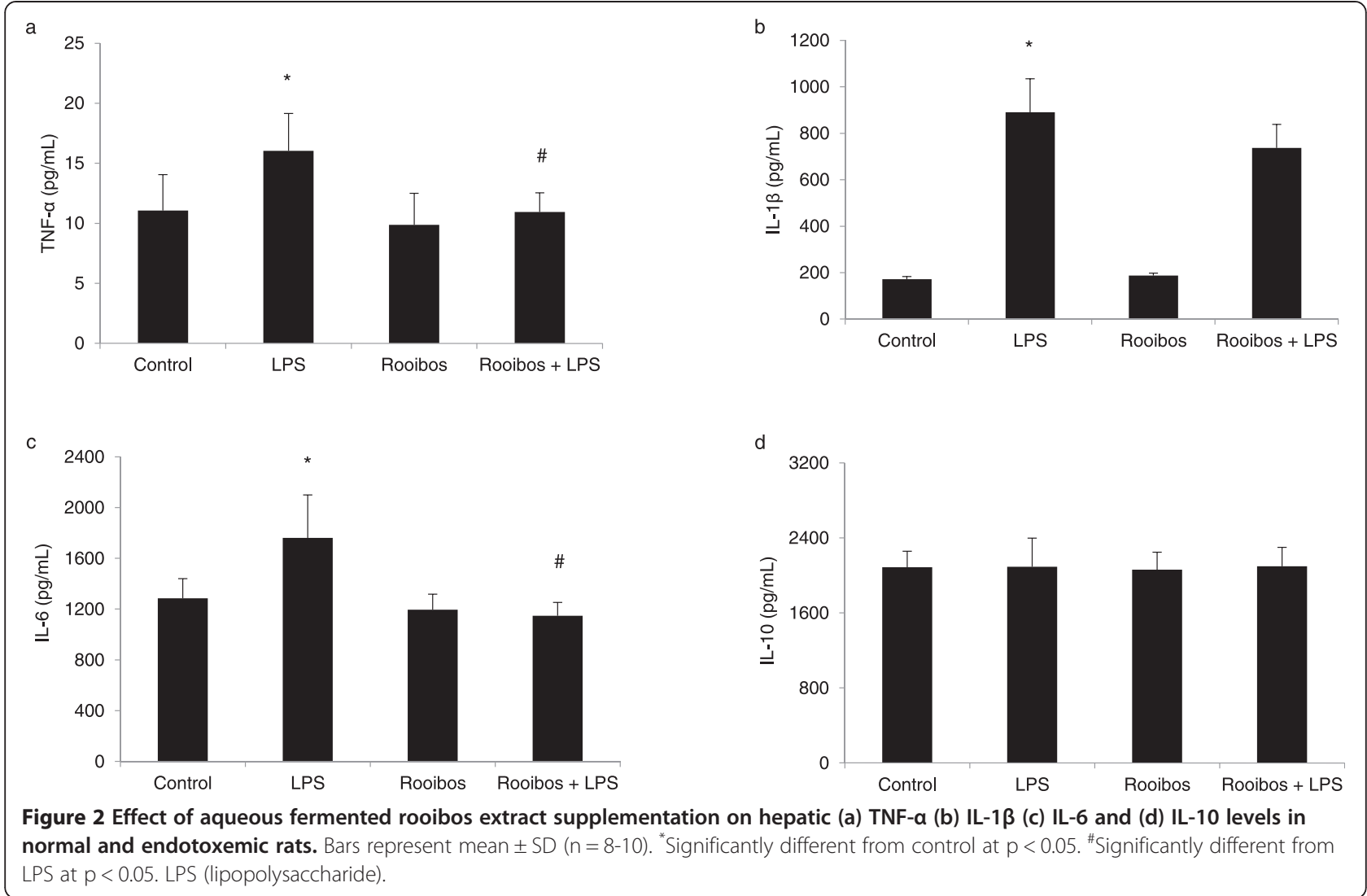

by rooibos is scarce. Thus, we are tempted to speculate that the protective effect shown by rooibos on cytokine formation in this study may be due to the plethora of antioxidant phytochemicals found in rooibos, since previous reports have shown that flavonoids found in rooibos such as luteolin, rutin and quercetin reduced LPS-induced expression of cytokines $[43,44]$. We also propose that the mechanism for the observed reduction in hepatic TNF- $\alpha$ and IL- 6 may involve the ability of antioxidant phytochemicals present in rooibos to inhibit the activation of Kupffer cells by LPS, leading to inhibition of TNF- $\alpha$ synthesis and subsequently synthesis of IL-6. Though the level of nuclear factor- $\kappa B$ (NF- $\kappa B$ ) was not measured in this study, given its central role in signaling and the inflammatory cascade, it is proposed that inhibiting the activation of NF- $\mathrm{\kappa B}$ by rooibos, may be an additional mechanism for the observed decrease in hepatic TNF- $\alpha$ and IL-6 level. IL-10 is an anti-inflammatory cytokine produced by monocytes and lymphocytes, while previous reports have indicated that it is antagonistic to TNF- $\alpha$ in its modulation of the inflammatory response [45]. IL-10 has been reported to down-regulate TNF- $\alpha$, as well as other cytokine production, by suppressing their gene expression in an autocrine-like feedback loop [46]. However in this study, we observed that the level of IL-10 was similar across all control and LPS-treated groups, indicating that the inhibition of TNF- $\alpha$ formation observed with rooibos extract supplementation may be independent of the activation of the feedback loop of IL-10.

Nitric oxide (NO) and superoxide anion $\left(\mathrm{O}_{2}{ }^{\cdot-}\right)$ are two free radicals secreted during activation of Kupffer cells under LPS insult. NO reacts with $\mathrm{O}_{2}{ }^{\cdot-}$ to form peroxynitrite which is a potent cytotoxic, oxidative agent that can elicit lipid peroxidation [47]. LPS-induced lipid peroxidation is an index of oxidative stress, and several previous studies have reported enhanced lipid peroxidation in many tissues (including liver, heart, brain, small intestine and stomach) of rats [2,33-35,48]. Under conditions of oxidative stress, reactive oxygen and nitrogen species (RONS) attack the polyunsaturated fatty acids (PUFAs) of cell membranes causing destabilization, disintegration and alteration in membrane fluidity and permeability, all events which increase the rate of protein degradation and eventually leads to cell lysis [40]. Decomposition products of lipid hydroperoxides such as MDA and 4-HNE can also cause chaotic cross-linkage with protein and nucleic acids, leading to oxidative protein and DNA damage [49]. In this study, plasma and hepatic $\mathrm{CD}$ and MDA, as markers of lipid peroxidation, were measured. While plasma and hepatic CD were unaffected by LPS treatment, elevated levels of plasma and hepatic MDA were observed. Pre-feeding rooibos extract for 
4 weeks in the LPS-challenged rats, inhibited the formation of MDA in the plasma and liver. A large number of in vitro studies have established the excellent free radical scavenging ability of rooibos, and this has been confirmed in many in vivo studies. The ability of rooibos to lower lipid peroxidation and modulate oxidative stress has been demonstrated in rat brain [50], liver [9,51,52], as well as in humans at risk $[10,11]$. Since rooibos is a polyphenol-rich herbal tea, its polyphenolic compounds may be able to bind RONS directly and scavenge them or act as sacrificial antioxidants to inhibit the lipid peroxidation cascade as seen in this study.

The impairment of the antioxidant defense system is a critical step in LPS-induced hepatic injury. Evidence has shown that a LPS insult is characterized by change in tissue and circulating antioxidant enzymes levels, as well as non-enzymatic antioxidants, including GSH $[33,34,40]$. In our study, plasma SOD and CAT were unaffected by LPS treatment, while activities of GPx and GR were significantly reduced. In the liver, the activity of SOD was inhibited by LPS treatment. This inhibition is not surprising since the $\mathrm{O}_{2}{ }^{--}$has been implicated as one of the toxic mediators responsible for most toxicities observed in LPS-induced cellular injury, and SOD, a metalloprotein, is a key enzyme involved in the protection of cells by spontaneously dismutating $\mathrm{O}_{2}{ }^{--}$to $\mathrm{H}_{2} \mathrm{O}_{2}$. The $\mathrm{H}_{2} \mathrm{O}_{2}$ produced by SOD is usually decomposed to water and oxygen by the hemoprotein CAT, localized in the peroxisomes. LPS treatment significantly increased the activity of hepatic CAT in this study. An increase that may be an adaptive physiological response to overproduction of $\mathrm{H}_{2} \mathrm{O}_{2}$ resulting from SOD action. GPx and GR are important enzymes of the glutathione defense system. While GPx catalyses the reduction of $\mathrm{H}_{2} \mathrm{O}_{2}$ and lipid hydroperoxides using GSH as a co-substrate, GR regenerates GSH from GSSG at the expense of NADPH. In this study, the activities of both GPx and GR were significantly depleted by LPS treatment, an indication of their inactivation and failure of the antioxidant enzymes to overcome the influx of RONS after LPS exposure [53]. Results from this study further showed that feeding rooibos for 4 weeks prior to the LPS challenge reversed the changes observed in the activities of SOD, CAT, GPx and GR in the liver. The modulation of the antioxidant enzymes activities observed in the LPS-challenged rats consuming rooibos could be ascribed to the direct quenching of RONS generated by LPS, since antioxidant components of rooibos are established free radical scavengers. Furthermore, the up-regulation and/or downregulation of the gene expression of the antioxidant enzymes may be an additional mechanism that should be elucidated in future studies. Reduced glutathione (GSH) is the major non-protein thiol in plant and animal cells. It is essential for the regulation of a variety of cellular functions, playing an important role in intracellular protection against ROS and other free radicals [54]. Because of its sulphydryl $(-\mathrm{SH})$ group, it can function as a nucleophile, forming conjugates with many xenobiotics and/or their metabolites and also serve as a reductant in the metabolism of hydrogen peroxide and other organic peroxides [55]. During interaction with free radicals, the $-\mathrm{SH}$ group of GSH becomes oxidized, leading to the formation of corresponding disulfide compound (GSSG). Thus, a depletion of GSH is usually associated with an increase in GSSG concentration and a lowered GSH: GSSG redox ratio during conditions of oxidative stress $[56,57]$. Results from the current study revealed a decrease in GSH (blood) and an increase in GSSG (liver) in rats challenged with LPS. These events invariably resulted in a decrease in the GSH:GSSG ratio in both tissues of LPS-challenged rats. Feeding rooibos to LPS-treated rats, restored the GSH:GSSG ratio to values comparable to those found in the negative control animals, indicating that rooibos extract is able to protect against LPS-induced glutathione imbalance. The protection shown by rooibos in this study is in agreement with previous studies where rooibos has been reported to improve the GSH:GSSG ratio in rat hearts subjected to ischaemia/reperfusion injury [58], rats oxidatively challenged with $t$-BHP [9] and human populations at the risk for cardiovascular diseases [11]. The ability to improve the GSH: GSSG ratio via increasing GSH (plasma) and/or decreasing GSSG (liver), shown by rooibos can be ascribed to the ability of their individual antioxidant components to quench free radicals and up-regulate the synthesis of GSH as suggested in some previous studies [59].

It is important to point out that since this study was conducted in male rats, it is possible that the results obtained may or may not be applicable to female rats. Several reports have shown gender-related differences in liver damage after various types of insults $[60,61]$. Some studies in animals reported a sex-related difference to oxidative stress and activities of cellular antioxidant enzymes which may be organ specific [62-64]. These studies showed that female animals may be less susceptible to oxidative stress-induced liver injury compared to male animals. Though gender-related differences in susceptibility to xenobiotic-induced liver injury is controversial and its specific mechanism(s) is still not fully understood, differences in circulating sex hormones, hepatic expression of sex hormone receptors and pattern of growth hormone secretion have all been mentioned to be responsible [61].

\section{Conclusion}

This study provides the first in vivo evidence of an antiinflammatory effect of rooibos in LPS-induced hepatic injury in rats. LPS-induced cytokine secretion has been shown to require the production of reactive oxygen and 
nitrogen species, resulting in lipid peroxidation as demonstrated in this study. Results from this study further demonstrates that rooibos is able to suppress LPStriggered oxidative stress and inflammatory responses in the liver by attenuating liver damage, lipid peroxidation, redox (GSH:GSSG) imbalance and pro-inflammatory cytokine secretion in a Wistar rat model. Rooibos contain important phytochemical constituents with excellent antioxidant properties which may in part, explain this observed anti-inflammatory activity. This suggest that rooibos may be of benefit in the prophylactic management of LPS-induced liver injury, however, future studies are necessary to fully examine the specific mechanisms underlying the protective effects shown by this herbal tea.

\begin{abstract}
Abbreviation
ALT: Alanine aminotransferase; ANOVA: Analysis of variance; AST: Aspartate aminotransferase; CAT: Catalase; CD: Conjugated dienes; DMACA: 4-(dimethylamino)-cinnamaldehyde; DTNB: 5,5'-dithiobis-2-nitrobenzoic acid; FRAP: Ferric ion reducing antioxidant power; GPx: Glutathione peroxidase; GR: Glutathione reductase; GSH: Reduced glutathione; GSSG: Oxidized glutathione; HPLC-DAD: High-performance liquid chromatography with diode array detection; IL: Interleukin; LDH: Lactate dehydrogenase; LPS: Lipopolysaccharide; MDA: Malondialdehyde, MPA, metaphosphoric acid; M2VP: 1-methyl-2-vinylpyridinium trifluoromethanesulfonate; NADPH: $\beta$-nicotinamide adenine dinucleotide phosphate reduced tetrasodium salt; NF-KB: Nuclear factor- KB; ORAC: Oxygen radical absorbance capacity; PCA: Perchloric acid; PUFA: Roly-unsaturated fatty acids; RONS: Reactive oxygen and nitrogen species; SOD: Superoxide dismutase; TBA: 2-thiobarbituric acid; TEAC: Trolox equivalent antioxidant capacity; TLR4: Toll-like receptor 4; TNF-a: Tumour necrosis factor- $a$.
\end{abstract}

\section{Competing interests}

The authors declare that they have no competing interests.

\section{Authors' contributions}

ORA contributed to conception, designed and perform all the experiments, and prepared the draft. $\mathrm{OOO}$ and JLM conceived the study and participated in its design. All authors analyzed the data and discussed and concluded the results. $\mathrm{OOO}$ and JLM provided final editing to the manuscript. All authors read and approved the final manuscript.

\section{Acknowledgments}

This work was supported by funding from the Cape Peninsula University of Technology and the Oxidative Stress Research Centre. The authors are grateful to Prof Jacques Van Rooyen for his useful advice in this study. The authors also thank Mr Fanie Rautenbach, Dr Novel Chegou and Dr Emma Thamahane-Katengua for technical assistance.

\section{Author details}

Oxidative Stress Research Centre, Institute of Biomedical and Microbial Biotechnology, Faculty of Health and Wellness Sciences, Cape Peninsula University of Technology, PO Box 1906 Bellville 7535, South Africa. ${ }^{2}$ Present Address: Redox Laboratory, Department of Human Biology, Faculty of Health Sciences, University of Cape Town, Anzio Road, Observatory 7925, Cape Town, South Africa.

Received: 1 July 2014 Accepted: 7 October 2014 Published: 13 October 2014

\section{References}

1. Larrosa M, Azorín-Ortuño M, Yanez-Gascon M, Garcia-Conesa M, Tomás-Barberán F, Espin J: Lack of effect of oral administration of resveratrol in LPS-induced systemic inflammation. Eur J Nutr 2011, 50(8):673-680.

2. Sebai H, Ben-Attia M, Sani M, Aouani E, Ghanem-Boughanmi N: Protective effect of resveratrol in endotoxemia-induced acute phase response in rats. Arch Toxicol 2009, 83(4):335-340
3. Sun S, Zhang H, Xue B, Wu Y, Wang J, Yin Z, Luo L: Protective effect of glutathione against lipopolysaccharide-induced inflammation and mortality in rats. Inflamm Res 2006, 55(11):504-510.

4. Sebai H, Ben-Attia M, Sani M, Aouani E, Ghanem-Boughanmi N: Protective effect of resveratrol on acute endotoxemia-induced nephrotoxicity in rat through nitric oxide independent mechanism. Free Radic Res 2008, 42:913-920.

5. Krzyzanowska J, Czubacka A, Oleszek W: Dietary Phytochemicals and Human Health. In Bio-Farms for Nutraceuticals: Functional Food and Safety Control by Biosensors. Edited by Giardi MT, Rea G, Berra B. New York: Springer; 2010:74-98

6. Joubert E, Gelderblom W, Louw A, De Beer D: South African herbal teas: Aspalathus linearis, Cyclopia spp. and Athrixia phylicoides - A review. J Ethnopharmacol 2008, 119(3):376-412.

7. Yoo KM, Lee $\mathrm{CH}$, Lee $\mathrm{H}$, Moon BK, Lee $\mathrm{CY}$ : Relative antioxidant and cytoprotective activities of common herbs. Food Chem 2008, 106(3):929-936.

8. Awoniyi DO, Aboua YG, Marnewick J, Brooks N: The Effects of rooibos (Aspalathus linearis), green tea (Camellia sinensis) and commercial rooibos and green tea supplements on epididymal sperm in oxidative Stress-induced rats. Phytother Res 2012, 26(8):1231-1239.

9. Ajuwon OR, Thamahane-Katengua E, Van Rooyen J, Oguntibeju OO, Marnewick $J$ : Protective effects of rooibos (Aspalathus linearis) and/or red palm oil (Elaeis guineensis) supplementation of tert-butyl hydroperoxide-induced oxidative hepatotoxicity in Wistar rats. Evid Based Compliment Alternat Med 2013, 2013(984273):19.

10. Nikolova V, Petrova S, Petkova V, Pavlova S, Michailova A, Georgieva T: Antioxidative effects of rooibos tea on workers occupationally exposed to lead. Toxicol Lett 2007, 172:S120-S121.

11. Marnewick JL, Rautenbach F, Venter I, Neethling H, Blackhurst DM, Wolmarans P, Macharia M: Effects of rooibos (Aspalathus linearis) on oxidative stress and biochemical parameters in adults at risk for cardiovascular disease. J Ethnopharmacol 2011, 133(1):46-52.

12. Kunishiro K, Tai A, Yamamoto I: Effects of rooibos tea extract on antigen-specific antibody production and cytokine generation in vitro and in vivo. Biosci Biotechnol Biochem 2001, 65(10):2137-2145.

13. Hendricks R, Pool EJ: The in vitro effects of rooibos and black tea on immune pathways. J Immunoassay Immunochem 2010, 31(2):169-180.

14. Mueller M, Hobiger S, Jungbauer A: Anti-inflammatory activity of extracts from fruits, herbs and spices. Food Chem 2010, 122(4):987-996.

15. Marnewick $J$, Joubert E, Swart P, van der Westhuizen F, Gelderblom WC: Modulation of hepatic drug metabolizing enzymes and oxidative status by rooibos (Aspalathus linearis) and honeybush (Cyclopia intermedia), green and black (Camellia sinensis) teas in rats. J Agric Food Chem 2003, 51(27):8113-8119.

16. Singleton $V L$, Orthofer R, Lamuela-Raventós RM: Analysis of total phenols and other oxidation substrates and antioxidants by means of folin-ciocalteu reagent. Methods Enzymol 1999, 299:152-178.

17. Treutter D: Chemical reaction detection of catechins and proanthocyanidins with 4-dimethylaminocinnamaldehyde. J Chromatogr A 1989, 467:185-193.

18. Mazza G, Fukumoto L, Delaquis P, Girard B, Ewert B: Anthocyanins, phenolics, and color of Cabernet franc, Merlot, and Pinot noir wines from British Columbia. J Agric Food Chem 1999, 47:4009-4017.

19. Ou B, Hampsch-Woodill M, Prior RL: Development and validation of an improved oxygen radical absorbance capacity assay using fluorescein as the fluorescent probe. J Agric Food Chem 2001, 49:4619-4626.

20. Re R, Pellegrini N, Proteggente A, Pannala A, Yang M, Rice-Evans C: Antioxidant activity applying an improved ABTS radical cation decolorization assay. Free Radic Biol Med 1999, 26:1231-1237.

21. Benzie IFF, Strain J: The ferric reducing ability of plasma (FRAP) as a measure of antioxidant power: the FRAP assay. Anal Biochem 1996, 239:70-76.

22. Bramati L, Minoggio M, Gardana C, Simonetti P, Mauri P, Pietta P: Quantitative characterization of flavonoid compounds in Rooibos tea (Aspalathus linearis) by LC-UV/DAD. J Agric Food Chem 2002, 50:5513-5519.

23. Ohsaki Y, Shirakawa H, Hiwatashi K, Furukawa Y, Mizutani T, Komai M: Vitamin K suppresses lipopolysaccharide-induced inflammation in the rat. Biosci Biotechnol Biochem 2006, 70:926-932.

24. Robles-Sanchez M, Astiazaran-Garcia H, Martin-Belloso O, Gorinstein S, Alvarez-Parrilla E, De la Rosa LA, Yepiz-Plascencia G, Gonzalez-Aguilar G: Influence of whole and fresh-cut mango intake on plasma lipids and antioxidant capacity of healthy adults. Food Res Int 2011, 44:1386-1391. 
25. Khoschsorur G, Winklhofer-Roob B, Rabl H, Auer T, Peng Z, Schaur R: Evaluation of a sensitive HPLC method for the determination of malondialdehyde, and application of the method to different biological materials. Chromatographia 2000, 52:181-184.

26. Recknagel RO, Glende E Jr: Spectrophotometric detection of lipid conjugated dienes. Methods Enzymol 1984, 105:331-337.

27. Aebi H: Catalase in vitro. Methods Enzymol 1984, 105:121-126.

28. Crosti N, Servidei T, Bajer J, Serra A: Modification of the 6hydroxydopamine technique for the correct determination of superoxide dismutase. J Clin Chem Clin Biochem 1987, 25:265-266.

29. Ellerby LM, Bredesen DE: Measurement of cellular oxidation reactive oxygen species and antioxidant enzymes during apoptosis. Methods Enzymol 2000, 322:413-421.

30. Staal GEJ, Visser J, Veeger C: Purification and properties of glutathione reductase of human erythrocytes. Biochim Biophys Acta 1969, 185:39-48.

31. Tietze F: Enzymic method for quantitative determination of nanogram amounts of total and oxidized glutathione: Applications to mammalian blood and other tissues. Anal Biochem 1969, 27:502-522

32. Cheng YJ, Yang BC, Liu MY: Lead increases lipopolysaccharide-induced liver injury through tumor necrosis factor-a overexpression by monocytes/ macrophages: role of protein kinase $C$ and p42/44 mitogen-activated protein kinase. Environ Health Perspect 2006, 114:507-513.

33. Kaur G, Tirkey N, Bharrhan S, Chanana V, Rishi P, Chopra K: Inhibition of oxidative stress and cytokine activity by curcumin in amelioration of endotoxin-induced experimental hepatotoxicity in rodents. Clin Exp Immunol 2006, 145:313-321.

34. Kaur G, Tirkey N, Chopra K: Beneficial effect of hesperidin on lipopolysaccharide-induced hepatotoxicity. Toxicology 2006, 226:152-160.

35. Sebai H, Sani M, Yacoubi MT, Aouani E, Ghanem-Boughanmi N, Ben-Attia M: Resveratrol, a red wine polyphenol, attenuates lipopolysaccharide-induced oxidative stress in rat liver. Ecotoxicol Environ Saf 2010, 73:1078-1083.

36. Amat N, Upur H, Blazekovic B: In vivo hepatoprotective activity of the aqueous extract of Artemisia absinthium L. against chemically and immunologically induced liver injuries in mice. J Ethnopharmacol 2010, 131:478-484.

37. Qu XJ, Xia X, Wang YS, Song MJ, Liu LL, Xie YY, Cheng YN, Liu XJ, Qiu LL, Xiang L: Protective effects of Salvia plebeia compound homoplantaginin on hepatocyte injury. Food Chem Toxicol 2009, 47:1710-1715.

38. Sugimoto K, Sakamoto S, Nakagawa K, Hayashi S, Harada N, Yamaji R, Nakano $Y$, Inui $\mathrm{H}$ : Suppression of inducible nitric oxide synthase expression and amelioration of lipopolysaccharide-induced liver injury by polyphenolic compounds in Eucalyptus globulus leaf extract. Food Chem 2011, 125:442-446.

39. Kao ES, Hsu JD, Wang CJ, Yang SH, Cheng SY, Lee HJ: Polyphenols extracted from Hibiscus sabdariffa L. inhibited lipopolysaccharide-induced inflammation by improving antioxidative conditions and regulating cyclooxygenase-2 expression. Biosci Biotechnol Biochem 2009, 73(2):385-390.

40. Bharrhan S, Chopra K, Rishi P: Vitamin E supplementation modulates endotoxin-induced liver damage in a rat model. Am J Biomed Sci 2010, 2(1):51-62.

41. Hsieh CH, Frink M, Hsieh YC, Kan WH, Hsu JT, Schwacha MG, Choudhry MA, Chaudry IH: The role of MIP-1a in the development of systemic inflammatory response and organ injury following trauma hemorrhage. J Immuno/ 2008, 181(4):2806-2812.

42. Jaeschke $\mathrm{H}$ : Reactive oxygen and mechanisms of inflammatory liver injury. J Gastroenterol Hepatol 2000, 15(7):718-724.

43. Takahashi K, Morikawa A, Kato Y, Sugiyama T, Koide N, Mu MM, Yoshida T, Yokochi T: Flavonoids protect mice from two types of lethal shock induced by endotoxin. FEMS Immunol Med Microbiol 2001, 31(1):29-33.

44. Kotanidou A, Xagorari A, Bagli E, Kitsanta P, Fotsis T, Papapetropoulos A, Roussos C: Luteolin reduces lipopolysaccharide-induced lethal toxicity and expression of pro-inflammatory molecules in mice. Am J Respir Crit Care Med 2002, 165(6):818-823.

45. Jaffer $U$, Wade R, Gourlay T: Cytokines in the systemic inflammatory response syndrome. HSR Proc Intensive Care Cardiovasc Anesth 2010, 2(3):161-175.

46. Oberholzer A, Oberholzer C, Moldawer LL: Interleukin-10: a complex role in the pathogenesis of sepsis syndromes and its potential as an anti-inflammatory drug. Crit Care Med 2002, 30(1):S58-S63.

47. Halliwell B, Gutteridge JMC: Free Radicals in Biology and Medicine. Oxford, UK: Oxford University Press; 2007
48. Depboylu B, Giriş M, Olgaç V, Doğru-Abbasoğlu S, Uysal M: Response of liver to lipopolysaccharide treatment in male and female rats. Exp Toxicol Pathol 2013, 65(5):645-650.

49. Pari $L$, Shagirtha $K$ : Hesperetin protects against oxidative stress related hepatic dysfunction by cadmium in rats. Exp Toxicol Pathol 2010 64(5):513-520.

50. Inanami O, Asanuma T, Inukai N, Jin T, Shimokawa S, Kasai N, Nakano M, Sato F, Kuwabara M: The suppression of age-related accumulation of lipid peroxides in rat brain by administration of rooibos tea (Aspalathus linearis). Neurosci Lett 1995, 196(1-2):85-88.

51. Ulicna O, Greksák M, Vancova O, Zlatos L, Galbavy S, Bosek P, Nakano M: Hepatoprotective effect of rooibos tea (Aspalathus linearis) on $\mathrm{CCl}_{4}$-induced liver damage in rats. Physiol Res 2003, 52(4):461-466.

52. Ulicna O, Vancova O, Bozek P, Carsky J, Sebekova K, Boor P, Nakano M, Greksák M: Rooibos tea (Aspalathus linearis) partially prevents oxidative stress in streptozotocin-induced diabetic rats. Physiol Res 2006, 55(2):157-164.

53. Kono Y, Fridovich I: Superoxide radical inhibits catalase. J Biol Chem 1982, 257:5751-5754.

54. Naik SR, Thakare VN, Patil SR: Protective effect of curcumin on experimentally induced inflammation, hepatotoxicity and cardiotoxicity in rats: Evidence of its antioxidant property. Exp Toxicol Pathol 2011, 63:419-431.

55. Suntres ZE: Liposomal antioxidants for protection against oxidant-induced damage. J Toxicol 2011, 2011(152474):16.

56. Dickinson DA, Forman HJ: Glutathione in defense and signaling. Ann NY Acad Sci 2002, 973(1):488-504.

57. Marnewick JL, Van Der Westhuizen FH, Joubert E, Swanevelder S, Swart $P$, Gelderblom WCA: Chemoprotective properties of rooibos (Aspalathus linearis), honeybush (Cyclopia intermedia) herbal and green and black (Camellia sinensis) teas against cancer promotion induced by fumonisin B1 in rat liver. Food Chem Toxicol 2009, 47(1):220-229.

58. Pantsi W, Marnewick J, Esterhuyse A, Rautenbach F, van Rooyen J: Rooibos (Aspalathus linearis) offers cardiac protection against ischaemia/reperfusion in the isolated perfused rat heart. Phytomedicine 2011, 18:1220-1228.

59. Moskaug JU, Carlsen H, Myhrstad MCW, Blomhoff R: Polyphenols and glutathione synthesis regulation. Am J Clin Nutr 2005, 81(1):277S-283S.

60. Harada H, Bharwani S, Pavlick KP, Korach KS, Grisham MB: Estrogen receptor-alpha, sexual dimorphism and reduced-size liver ischemia and reperfusion injury in mice. Pediatr Res 2004, 55:450-456.

61. Yokoyama $Y$, Nimura $Y$, Nagino M, Bland Kl, Chaudry $\mathrm{H}$ : Current understanding of gender dimorphism in hepatic pathophysiology. J Surg Res 2005, 128:147-156.

62. Chen Y, Ji LL, Liu TY, Wang ZT: Evaluation of gender-related differences in various oxidative stress enzymes in mice. Chinese J Physiol 2011, 54:385-390.

63. Chang KA, Lin IC, Sheen JM, Chen YC, Chen CC, Tain YL, Hsieh CS, Huang $\mathrm{LT}$ : Gender differences of oxidative stress to cholestatic liver and kidney injury in young rats. Pediatr Neonatol 2013, 54:95-101.

64. Pattar J, Shridhar NB, Sanganal J, Satyanarayana ML, Suhasini K, Kadagi M: Gender difference of oxidative stress to $\mathrm{CCl}_{4}$ induced hepatoxicity and protective role of Ficus virens in rats: A biochemical study. J Cell Tissue Res 2013, 13:3971-3975.

doi:10.1186/1472-6882-14-392

Cite this article as: Ajuwon et al.: Amelioration of lipopolysaccharideinduced liver injury by aqueous rooibos (Aspalathus linearis) extract via inhibition of pro-inflammatory cytokines and oxidative stress. $B M C$ Complementary and Alternative Medicine 2014 14:392. 